\title{
STATUS OF THE INJECTOR SYSTEM FOR THE SYNCHROTRON LIGHT SOURCE ANKA
}

\author{
D. Einfeld, U.Ristau, R. Rossmanith \\ Forschungszentrum Karlsruhe, P.O. 3640, D-76021 Karlsruhe, Germany \\ N. Hertel, S. P. Møller, Institute of Storage Ring Facilities, Aarhus University, \\ DK-8000 Aarhus, Denmark \\ H.Bach, B.R. Nielsen, L. Praestegaard, Danfysik A/S, DK-Jyllinge, Denmark
}

\begin{abstract}
ANKA is a $2.5 \mathrm{GeV}$ synchrotron light source under construction at the Forschungszentrum Karlsruhe. The facility consists of a $53 \mathrm{MeV}$ microtron, an injection line, a $500 \mathrm{MeV}$ booster synchrotron, and the ejection line. The whole injector is being built as a turn key system by the industry (Danfysik, Denmark). The interface between the injector and the storage ring is the entrance of the injection septum. The $53 \mathrm{MeV}$ racetrack microtron is already commissioned. It delivers a beam of $53 \mathrm{MeV}, 16$ $\mathrm{mA}, 6 \mathrm{~Hz}$ and $1.2 \mu \mathrm{s}$. The installation of the injection line as well as the booster synchrotron is under way and the commissioning of the booster synchrotron will start in May 99. We expect to get an accelerated beam to 500 MeV before summer 1999.
\end{abstract}

\section{INTRODUCTION}

The ANKA injector is a $500 \mathrm{MeV}$ booster synchrotron for the $2.5 \mathrm{GeV}$ ANKA synchrotron which presently is under construction at Forschungszentrum Karlsruhe (FZK), Germany [1]. The injector complex (fig. 1) consists of a $53 \mathrm{MeV}$ microtron pre-injector, a $500 \mathrm{MeV}$ booster synchrotron, an injection line between the microtron and booster synchrotron, and a ejection line from the booster synchrotron to the ANKA storage ring. The microtron delivers an electron pulse with a duration of $0.5-1.2 \mu \mathrm{s}$ and a current of more than $10 \mathrm{~mA}$. The multi-turn injection process leads to a stored electron current of more than $15 \mathrm{~mA}$ in the booster synchrotron. The extracted electron pulse has a duration of $\sim 56 \mathrm{~ns}$, a current of more than $7.5 \mathrm{~mA}$ and an emittance of 0.15 $\mathrm{mm} \mathrm{mrad}$. The whole injection cycle is repeated with a rate of $1 \mathrm{~Hz}$. The microtron has been commissioned at its final position in ANKA. The assembling of the booster will be done in April 99 and a $500 \mathrm{MeV}$ accelerated beam is expected by summer 99. A detailed description of the optics of the booster synchrotron is presented elsewhere [2].

\section{THE PRE-INJECTOR}

The schematic layout of the microtron is shown in fig. 2, 3 and 4, while its main parameters are listed in table 1 . The E-gun is a $70 \mathrm{keV}$ spherical pierce type with a $\mathrm{BaO}$ cathode. The maximum gun current is around $500 \mathrm{~mA}$, with a pulse length of $5 \mu$ s.

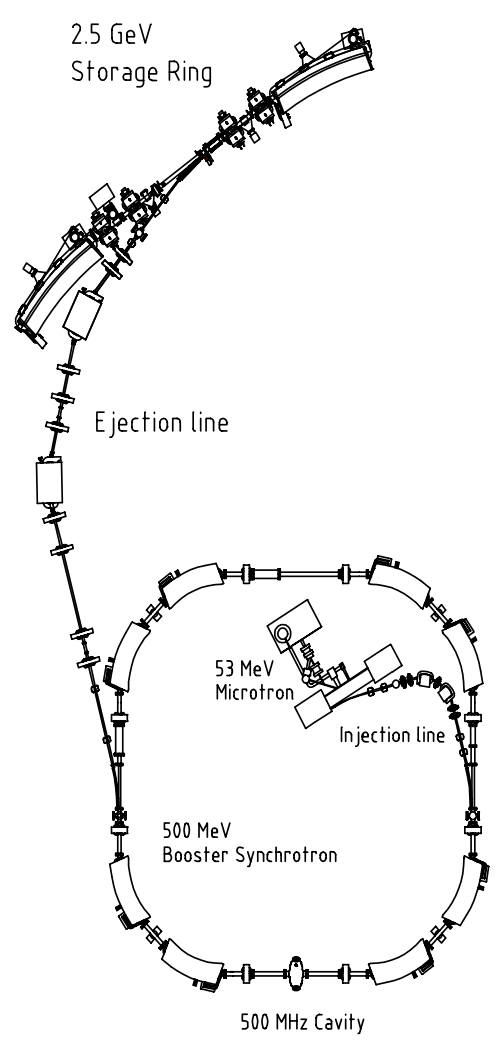

Figure 1: The injector complex of the ANKA project

Behind the E-gun the chopper is located, this will give the beam the $500 \mathrm{MHz}$ structure according to the RF-system of the booster synchrotron.

Starting at the E-gun the electron beam is guided by a constant solenoid field and a horizontal focussing quadrupol singlet. Two achromatic $45^{\circ}$ bending magnets deflect the beam to the linac axis. The linac is a side coupled $3 \mathrm{GHz}$ standing wave Los Alamos Type with $7+2 * 1 / 2$ Cells. The parameters of the linac are listed in table 1 . After the first linac pass the beam is reversed and in the second linac pass accelerated in the other direction. After 10 passes through the linac the beam is extracted with a constant energy of $53 \mathrm{MeV}$ with the help of a $15^{\circ}$ bending magnet. Fig. 3 shows the top view of the microtron. In the tracks $1-9$ horizontal and vertical steerers are located which allow to steer the beam through the machine. 


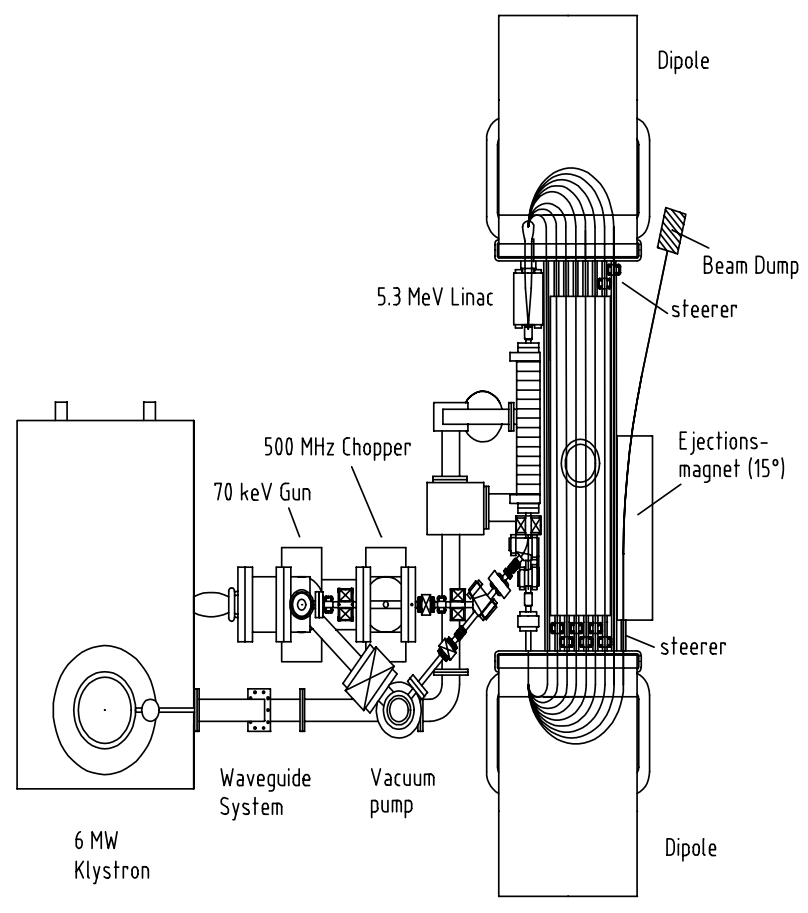

Figure 2: Outline of the ANKA microtron

Table 1: Main parameters of the racetrack microtron

\begin{tabular}{|l|c|}
\hline Injection energy & $70 \mathrm{keV}$ \\
\hline No. of Linac passes & 10 \\
\hline Energy gain per path & $5.3 \mathrm{MeV}$ \\
\hline Frequency & $2.998 \mathrm{GHz}$ \\
\hline Final electron energy & $53 \mathrm{MeV}$ \\
\hline Emittance (hor/ver) & $\bullet 0.2 \mathrm{~mm} \mathrm{mrad}$ \\
\hline Energy spread & $<0.3 \%$ \\
\hline Pulse current & $10 \mathrm{~mA}$ \\
\hline Pulse length & $0.4-1.4 \mu \mathrm{s}$ \\
\hline Repetition rate & $0-10 \mathrm{~Hz}$ \\
\hline Klystron & $\mathrm{CPI} / \mathrm{VSS}-8262 \mathrm{E}$ \\
\hline Modulator & Line type pulser \\
\hline RF-power /peak & $6 \mathrm{MW}$ \\
\hline Q-value of linac & 18000 \\
\hline Length of linac & $0.4 \mathrm{~m}$ \\
\hline Phase acceptance & $13^{\circ}$ \\
\hline Coupling & Side coupled \\
\hline
\end{tabular}

The RF-power for running the linac is delivered by a 6 MW-klystron fed by a modulator consisting of a line type pulser. The energy for the modulator is stored in a pulse forming network which delivers a primary voltage to a 1:10 pulse transformer. The klystron energy is transported to the linac through a SF 6 filled wave guide system. Within the wave guide system is a $-28 \mathrm{~dB}$ circulator which protects the klystron from being damaged by reflected RF-power of the linac. A bi-directional coupler is located at the input coupler of the linac. The reflected power signal and the RF-pulse are shown in fig. 5. The RF-pulse has a power of $\sim 2.5 \mathrm{MW}$ and a flat top of more than $1.5 \mu$ s duration.

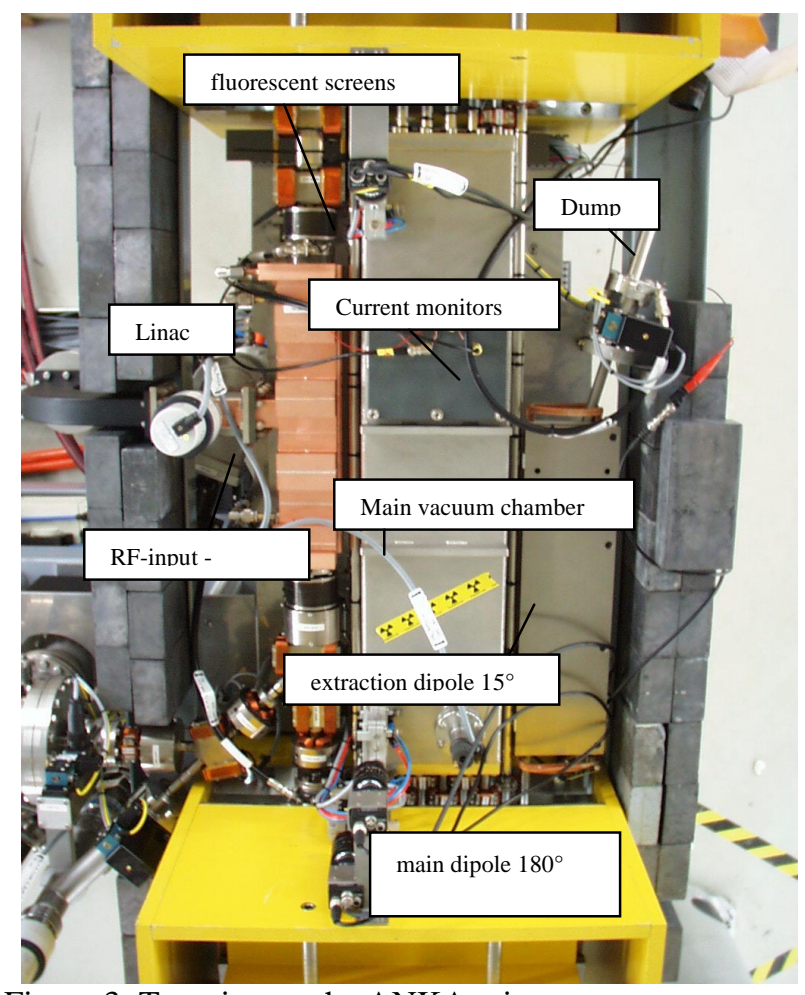

Figure 3: Top view to the ANKA microtron

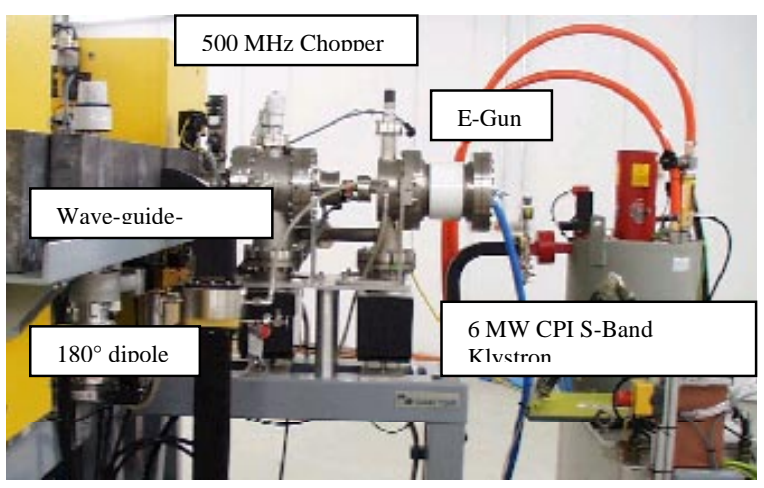

Figure 4: Microtron injection, klystron, linac wave guide, E-gun, $500 \mathrm{MHz}$ chopper

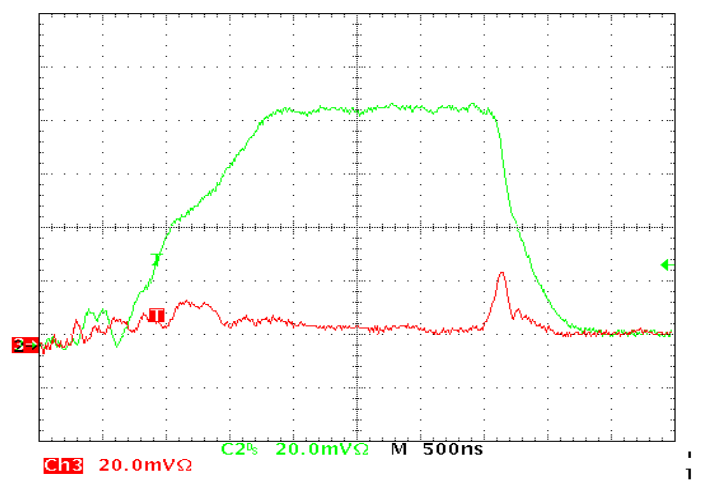

Figure 5: $3 \mathrm{GHz}$ signal measured with a pickup at the end of the linac (green line). Reflected power signal measured in the wave guide (red line) 
The diagnostic tools for measuring the properties of the beam within the microtron are summarized in table 2 . There are overall 9 current transformers distributed in the racetracks. Three fluorescent screens are located at 10 $\mathrm{MeV}$ (track 2) and two additional ones at $15 \mathrm{MeV}$ (track $3)$.

Table 2: The diagnostic tools of the Microtron

\begin{tabular}{|l|l|l|}
\hline Diagnostic tool & Location & Number \\
\hline Current transformer & & 9 \\
\hline Sync. light monitor & 180-Bend & 1 \\
\hline Fluorescent viewer & track 2, track 3 & 3 \\
\hline RF-Pick-up & Linac & 2 \\
\hline Bi-directional coupler & Wave guide & 2 \\
\hline
\end{tabular}

Only the fourth track (20 MeV) has no diagnostic tools. From the fifth to the tenth track the beam can be observed either through the emitted synchrotron light or using the current monitors. The signals from the current monitor at the $5^{\text {th }}, 6^{\text {th }}, 8^{\text {th }}$ and $10^{\text {th }}$ track are presented in fig. 6 . From this figure it follows that the beam losses between turns 5 to 8 are relatively small. A CCD camera is used to detect the synchrotron light which is observed in one of the main dipoles (see fig. 7).

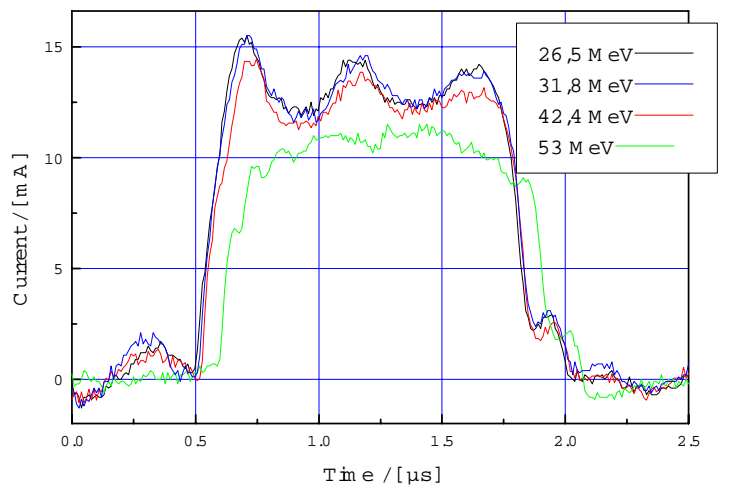

Figure 6: Pulse of the current monitor within the tracks 5, 6,8 and 10

The extracted beam has a pulse width of up to $1.2 \mu$ s and an average amplitude of $11 \mathrm{~mA}$. The vertical focussing of the microtron was modified during the commissioning by changing the gradient of one of the main dipoles.

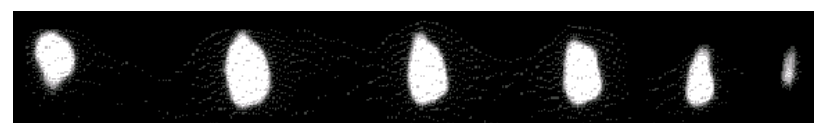

Figure 7: The synchrotron light of the accelerated beam within the turns 4 to 10 (from right to left)

Figure 8 shows the size of the extracted beam measured at the beam dump. For this picture the dump was covered with a grid of a spacing of $1 \mathrm{~mm}$. The spot size is about 3 x $3 \mathrm{~mm}$ which is close to the theoretical value of $2 \times 2$ $\mathrm{mm}$. The specifications of the extracted beam are summarized in table 3.

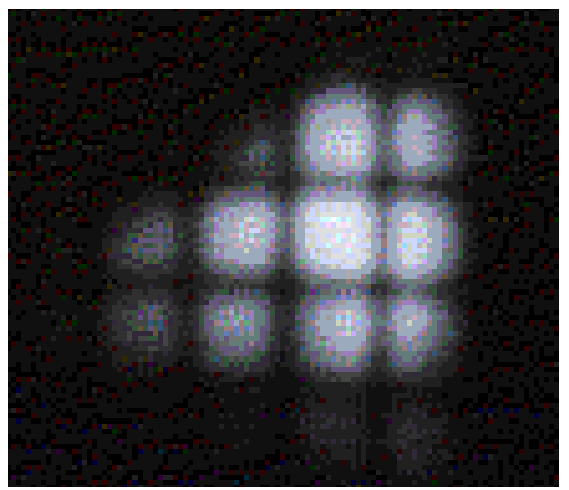

Figure 8: The $53 \mathrm{MeV}$ extracted electron beam. The grid constant is $1 \mathrm{~mm}$.

Table 3: Specifications of the extracted microtron beam

\begin{tabular}{|c|c|c|c|}
\hline Item & Design & $\begin{array}{c}\text { Guaran- } \\
\text { teed }\end{array}$ & $\begin{array}{c}\text { Commis- } \\
\text { sioning }\end{array}$ \\
\hline Current/ mA & 15 & 10 & 16 \\
\hline Pulse length / $\mu \mathrm{s}$ & 1 & 1 & 1.6 \\
\hline Energy/ MeV & 53 & 53 & 53 \\
\hline $\begin{array}{c}\text { Repetition rate/ } \\
\mathrm{Hz}\end{array}$ & 10 & 10 & 6 \\
\hline $\begin{array}{c}\text { Frequenz } \\
\text { modulation/MHz }\end{array}$ & 500 & 500 & 500 \\
\hline \multicolumn{2}{|c}{}
\end{tabular}

\section{BOOSTER SYNCHROTRON}

The production of all items for the booster synchrotron and the transfer lines is finished. 8 subsystems, according to the number of bending magnets, will be assembled at the manufacturer and shipped to the site of ANKA. The installation of the subsystems at ANKA is foreseen for the end of April. The RF-System (cavitiy, low-levelelectronic, etc.) will be delivered by Sincrotrone Trieste. The acceptance test of the RF-system has been performed and the assembling at ANKA will take place also at the end of April. The control system for running the booster will be built by a collaboration of FZK and Jozef-StefanInstitute in Ljubljana, Slovenia. A test of this system has already been made with the commissioning of the microtron. The part for controlling the booster will also be finished by May 99. The commissioning of the booster synchrotron will start in May 99 and an accelerated beam is expected for summer 99.

\section{REFERENCES}

[1] D. Einfeld et al., Status of the $2.5 \mathrm{GeV}$ Light Source ANKA, these proceedings

[2] H.Bach, D. Einfeld, L.Praestegaard, N. Hertel, U. Ristau, R. Rossmanith; The ANKA Injector EPAC 98, June 22-26, Stockholm, Sweden (1998) 